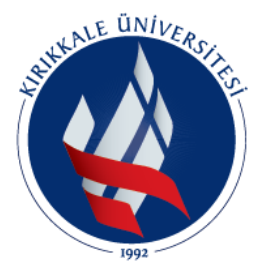

MÜHENDISLIK FAKÜLTESI

Cilt/Volume:10
Sayı/Issue:2
Uluslararası Mühendislik Araştırma ve

Geliştirme Dergisi

International Journal of Engineering Research and Development

https://doi.org/10.29137/umagd.349649

Araştırma Makalesi / Research Article

\title{
Experimental Evaluation of Performance for Micro Wind Turbines by Using Permanent Magnets
}

\begin{tabular}{|c|c|c|}
\hline \multicolumn{3}{|c|}{ Murat ARI $^{1}$, Hayati MAMUR ${ }^{2}$} \\
\hline \multicolumn{3}{|c|}{$\begin{array}{l}{ }^{I} \text { Cankiri Karatekin University, Faculty of Engineering, Electrical and Electronics Engineering, Cankiri / TURKEY } \\
{ }^{2} \text { Manisa Celal Bayar University, , Faculty of Engineering, Electrical and Electronics Engineering, Manisa /TURKEY }\end{array}$} \\
\hline Başvuru/Received: 06/11/2017 & Kabul/Accepted: 17/05/2018 & Son Versiyon/Final Version: 29/06/2018 \\
\hline
\end{tabular}

\begin{abstract}
Permanent magnet synchronous generators with interior rotor (IR-PMSGs) have been widely preferred in micro wind turbines (MWTs). Customers demand high output power of the MWTs. Therefore, in this study, performance analyses and optimizations of two IR-PMSG rotors were practically carried out to increase the output power of the MWTs by employing N35 and N42 Neodymium-Iron-Boron (NdFeB) permanent magnets (PMs) with same geometry used on IR-PMSG rotor surfaces. For this purpose, two IR-PMSG rotors were designed with same geometry and applied to a pole shifting reduction technique to decrease their cogging torque on the IR-PMSGs as well. According to the obtained results, comparing the performances of the IR-PMSGs with both N35 and N42 NdFeB PMs on a MWT with regards to their power coefficients, an increase of $18.6 \%$ in power coefficient of the IR-PMSG with N42 NdFeB PMs was calculated.
\end{abstract}

\section{Key Words}

performance evaluation; permanent magnet; permanent magnet synchronous generator; micro wind turbine, wind energy 


\section{INTRODUCTION}

Wind energy is a renewable energy resource. Today, conversion of wind energy into electrical energy by wind turbines (WTs) has been widely employed in the world (Mamur 2016). These WTs, commercially manufactured, is generally classified into two categories as small WTs (SWTs) and large WTs (LWTs) (Mamur et al. 2013; Mamur et al. 2017). The SWTs are also divided into three groups as micro WTs (MWTs), SWTs and small-medium WTs (S-MWTs) (Mamur 2015a). MWTs generate electrical energy until $1.5 \mathrm{~kW}$. In order to meet small electricity needs, they are commonly utilized in regions such as plateaus, vineyards, gardens, fattening farms and yachts, where there are no electricity networks (Mamur et al. 2015; Arıkan and Çam 2017).

In MWTs, induction generators (IGs) for generating electrical energy are often used (İskender and Genç 2009; Lebsir et al. 2015; Hostettler and Wang 2015). The PMSGs are designed different forms such as axial flux PMSGs (AF-PMSGs), interior rotor PMSGs (IR-PMSGs) and outer rotor PMSGs (OR-PMSGs) (Yildiriz and Aydemir 2009). Improving the energy density in PMSGs is provided through enhancing the efficiency of MWT. The energy density largely depends on rotor structures and permanent magnets (PMs). Designing PMSG as an IR-PMSG type boosts the energy density, output power and torque of PMSG; however, the design leads to the growth of the structure of the IR-PMSG (Tarimer and Ocak 2009).

The magnetic flux density of used PMs has a great effect on the output power and moment of PMSG as well (Petrow and Pyrhönen 2013). Lately, Neodymium-Ferrite-Boron ( $\mathrm{NdFeB}$ ) types PMs usually are preferred due to high magnetic capacity and cheaper costs (Coey 2012). Increase in the magnetic capacity of PMs reduces the size of PMSGs as well and then tower loads and blade dimensions of MWTs decrease (Tripathi at al. 2015). On the other hand, the NdFeB PMs being widely available commercially can be employed until $80^{\circ} \mathrm{C}$ (Petrow and Pyrhönen 2013; Löewe et al. 2015). Some PMs that can be utilized at high temperatures are also mentioned in literature (Kim at al. 2013).

In literature, performance effects on PMSGs of PMs manufactured in different forms and structures are discussed. The effects of ferrite PMs with low-cost on PMSG performance was investigated by Petrow and Pyrhönen (Petrow and Pyrhönen 2013). They obtained a characteristic of OR-PMSG with ferrite PM and then compared with an OR-PMSG with NdFeB PM. According to their results, they demonstrated that the OR-PMSG with ferrite PM cannot compete with the OR-PMSG with NdFeB PM in terms of performance coefficient values. Zhang et al. (Zahng et al. 2012) carried out a study that was about PM technologies for electrical motors used in automotive applications and emphasized that price drops in PMs would further improve the usage of the PMSG technologies in automotive. In another study, effects of the amount of PM materials were worked for an OR-PMSG with fractional slot winding by Sergeant and Bossche (Sergeant and Van den Bossche 2014). They calculated the efficiency of an OR-PMSG as a function of the size of PMs through keeping constant the mechanical air gap, the volume and the torque density. They observed significant changes for the efficiency of the OR-PMSG in the thickness variations of PMs until $2 \mathrm{~mm}$ but they expressed that the thickness variations of PMs within 2-5 mm ranges almost did not yield any change in the efficiency. In addition to these, Slusarek et al. (Sulusarek et al. 2014) examined performances of them for pumps and cooling fans in mining industry by simultaneously using both Samarium-Cobalt (SmCo) and NdFeB PMs on an IR-PMSG and achieved an increase in efficiency. However, they explained that two types PMs to be inserted on rotor surface at the same time brought some difficulties with regards to manufacturing. Dysprosium-free NdFeB and ferrite PMs in different structures analyzed from the point of efficiency, torque, flux weakening and active weight by McFarland et al. (McFarland et al. 2014). Kim et al. (Kim et al. 2014) recommended that L and C type rotor design would be better than others in order to produce high torque in usage the ferrite type PMs. Liu et al. (Liu et al. 2014) also suggested a low cost PMSG that was constructed soft magnetic composite and ferrite PMs for employing in residential applications. Lastly, Bianchini et al. (Bianchini et al. 2014) offered an optimized low cost hybrid rotor poles.

According to the given studies in the literature, the studies mainly focus on the increase in the performance of PMSGs and decrease in their weight. In the presented study, the performances of N35 and N42 PMs on an IR-PMSG in a MWT system were practically defined in order to increase the power and torque of the MWT. For this purpose, two different rotors with same geometry, one of them has N35 NdFeB PM rotor and the other has N42 NdFeB PM rotor, are designed and manufactured. Their cut-in wind speeds, power coefficients, cogging torques and output powers were individually tested and compared on a MWT system.

The presentation of the conducted study was carried out as follows: In the second section, materials and methods were explained in order to execute the design and applications. The results of experimental work were given in the third section. In the fourth section, the results were discussed and finally in the fifth section, the conclusions and future perspectives and extended studies were stated.

\section{MATERIALS AND METHODS}

\subsection{General specifications of PMSGs}

Typically PMSGs are composed of a rotor and three-phase stator. Contrary to PMSGs' small size and light weight, they provide high output power and torque (Tripathi et al. 2015). Their efficiency reaches up to 97\% and they are direct-drive (Lebsir et al. 2015). They are advantageous for their adaptable structure and simplicity in design, which makes them more preferable in small 
and medium power MWT applications (Daili et al. 2015; Chung and You 2015). Because PMs employed in MWTs are constructed using rare-earth materials, PMSGs are slightly expensive compared to IGs (Petrow and Pyrhönen 2013).

On the other hand, PMSGs offer the advantages of small size, direct drive, high efficiency, flexible rotor structure and wide range operating speed as mentioned before but cogging torque still remains as the main disadvantage (Mamur 2015b; Dosiek and Pillay 2007; Islam et al. 2009). The high cogging torque in MWTs requires higher wind speeds to generate electrical energy (Ani et al. 2013).

The efficiency of PMSGs are mainly depends on rotor structures. Classifications of PMSGs vary based on the employed rotor structure. OR-PMSGs rotor-stator gap can be changed in wide ranges although IR-PMSGs do not allow it. Similarly, OR-PMSGs are more flexible as they allow change in PM sizes (Lebsir et al. 2015). Embedded magnet structure of IR-PMSGs contributes to the gap decrease.

As the power of PMSGs in WTs increase, their speed is decreased due to the blade strain. The value of nominal torque rises more than the value of nominal power. Active parts of electrical machines generate torque and torque $T$ and active weight $M_{a}$ of PMSGs are as follows:

$T=k_{T} D^{2} L$

$M_{a}=k_{a}\left(r_{o}-r_{i}\right) D L$

where, $k_{t}$ and $k_{a}$ are constants, $D, L, r_{o}$ and $r_{i}$ are respectively average air gap diameter, machine length, and outer and inner radius of active parts. Determining an optimum point through air gap diameter, machine length, and, other and inner radius of active parts is of importance with respect to generated power and torque. Electromagnetic properties of PMSGs greatly depend on the number of slots per phase, shapes of PMs and slot width. (Chung and You 2015).

In recent years, PMSG usage in MWTs has become more and more common. PMSGs rotating at low speeds cause noise, vibration and cut-in speed problems in MWTs whereas PMSGs rotating at high speeds do not cause any serious problems (Bianchini et al. 2014; Chung and You 2015). Under normal operating conditions, torque vibration is a result of interaction with air gap flux density high harmonics caused by stator winding and rotor PMs while the cogging torque is the result of interaction with the PMs and stator slots. The same cogging torque affects the cut-in speed of MWT. There are many methods suggested in the literature to reduce the cogging torque (Dosiek and Pillay 2007; Mamur et al. 2014).

\subsection{PMs used in PMSGs}

$\mathrm{NdFeB}$, SmCo, Aluminum-Nickel-Cobalt (Alnico) and Ferrite are the commonly utilized type PMs in PMSGs (Vaimann et al. 2013; Skomski et al. 2013). NdFeB PMs have the lowest operating temperature of $80^{\circ} \mathrm{C}$ among commercially available PMs. Operating temperatures for Alnico, SmCo and Ferrite PMs are about 500, 250 and $200^{\circ} \mathrm{C}$, respectively. The eddy-current and hysteresis losses occurring in these PMs occur adversely affect the productivity of PMSGs (Pyrhönen et al. 2015). Moreover, the cost of NdFeB PMs is higher than others and there is the risk of loss of magnetization characteristic at high temperatures (Lebsir et al. 2015). When the datasheets of PM manufacturers for NdFeB, SmCo, Alnico and Ferrite type PMs, which have been started to be used recently, are inspected, the values of maximum magnetic flux density-magnetic field intensity $B H_{\max }\left(\mathrm{kJ} / \mathrm{m}^{3}\right)$ of these PMs are respectively about 470, 350, 80 and $40 \mathrm{~kJ} / \mathrm{m}^{3}$ (Petrow and Pyrhönen 2013; Ani et al. 2013). $B H_{\max }$ curve of NdFeB PMs stands out among rare-earth magnets.

$\mathrm{NdFeB}$ and SmCo PMs are known as rare-earth magnets. NdFeB PMs are also the third generation of rare-earth magnets. Today, they are the most widely used and mostly commercialized. Owing to the existence of Neodymium element in abundance and cheapness of Ferrite, NdFeB PMs are indispensable from a cost-performance perspective (Zhang et al. 2012; Skomski et al. 2013).

$\mathrm{NdFeB}$ magnets are manufactured both in sintered and bonded forms. While the sintered magnet forms present high magnetic properties, the properties of the bonded magnet form are low in magnetism (Löewe et al. 2015). Moreover, as a result of the metallurgical materials with active powder ingredients present within their structure, some measures are taken to reduce oxidation and corrosion involving surface coating techniques such as epoxy, nickel, cuprum and silver; however, this is not the case for $\mathrm{SmCo}$, Alnico and Ferrite type magnets because they are corrosion-resistant magnets.

On the other hand, placement of PMs on the rotor surface of PMSG varies according to the purpose of application. For the applications that require high power, torque and fast response, the surface mounted rotor PMs are preferred but in the field weakening applications, the embedded rotor PMs give better results (Petrow and Pyrhönen 2013).

\subsection{The designed and prototyped IR-PMSG}

An IR-PMSG given in Figure 1a was designed and manufactured as a prototype. The IR-PMSG was inserted in an MWT structure as shown in Figure 1b. Then its performance analyses with the MWT were carried out by means a truck (Mamur 2015a). 
Two different rotors having same geometry with both N35 and N42 NdFeB PMs were designed for the manufactured IR-PMSG. In order to reduce the cogging torque, the PMs were fixed on rotor surfaces by pole shifting technique (Islam et al. 2009). In the first rotor structure, N35 NdFeB type PMs were employed (Mamur 2015a). In the second rotor structure, N42 NdFeB type PMs were employed.

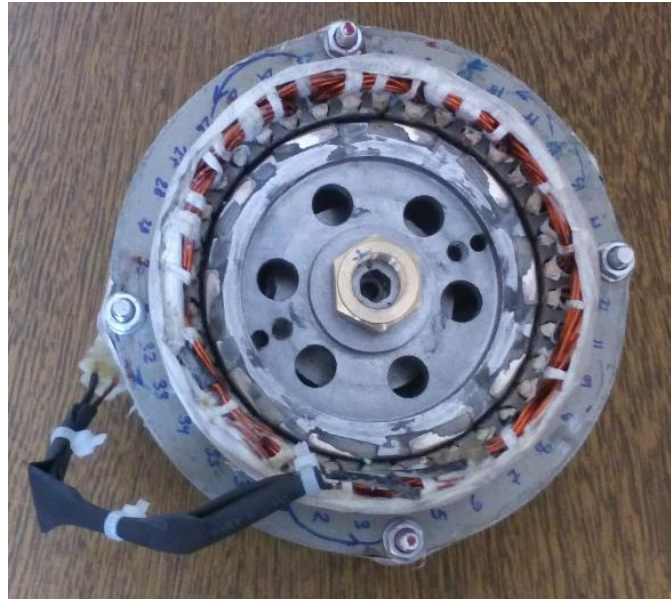

(a)

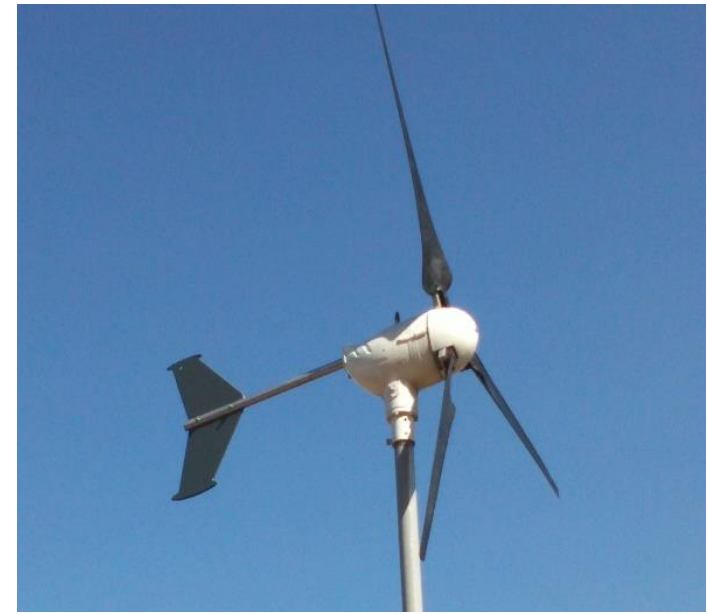

(b)

Figure 1. The designed (a) IR-PMSG and (b) the MWT system setup with three blades.

The stator winding of the IR-PMSG was a three phase, 12V AC. The output voltage of N35 and N42 NdFeB PMs varied within 10 to $45 \mathrm{~V}$ AC range depending on the different wind speeds recorded in the truck test. An integer slot winding technique was applied to the stator with 36 slots and its shaft was manufactured from stainless steel. The rotors designed for the IR-PMSG were mounted and then its effects on the performance of MWT were analyzed in detail. Dimensions and properties of the designed rotors, stator and the utilized MWT were given in Table $\mathbf{1 .}$

Table 1. Dimensions and properties of the designed rotors, stator and the utilized MWT.

\begin{tabular}{|l|l|l|l|l|l|}
\hline \multicolumn{2}{|l|}{ Rotor } & \multicolumn{2}{l|}{ Stator } & \multicolumn{2}{l|}{ MWT } \\
\hline Properties & Value & Properties & Value & Properties & Value \\
\hline Shaft diameter & $20 \mathrm{~mm}$ & $\begin{array}{l}\text { The number of } \\
\text { stator slots }\end{array}$ & 36 & Blade diameter & $1.24 \mathrm{~m}$ \\
\hline Shaft length & $110 \mathrm{~mm}$ & $\begin{array}{l}\text { Stator outer } \\
\text { diameter }\end{array}$ & $150 \mathrm{~mm}$ & Wing sweep area & $1.207 \mathrm{~m}^{2}$ \\
\hline Number of poles & 12 & $\begin{array}{l}\text { Stator inner } \\
\text { diameter }\end{array}$ & $99 \mathrm{~mm}$ & Number of wings & 3 \\
\hline Material & $1040 \mathrm{steel}$ & $\begin{array}{l}\text { Stator length } \\
\text { Air gap }\end{array} 1 \mathrm{~mm}$ & $20 \mathrm{~mm}$ & Body material & Aluminum \\
\hline $\begin{array}{l}\text { Bearing inside } \\
\text { diameter }\end{array}$ & $20 \mathrm{~mm}$ & $\begin{array}{l}\text { Slot opening } \\
\text { width }\end{array}$ & $3 \mathrm{~mm}$ & $\begin{array}{l}\text { The direction of } \\
\text { rotation }\end{array}$ & Clockwise \\
\hline $\begin{array}{l}\text { Bearing outside } \\
\text { diameter }\end{array}$ & $40 \mathrm{~mm}$ & Slot height & $11 \mathrm{~mm}$ & Braking system & Electrical \\
\hline
\end{tabular}

\subsection{The PMs employed in the design and their properties}

The sizes of N35 and N42 PMs employed in the design were determined The sizes of N35 and N42 PMs employed in the design were determined to be $20 \mathrm{~mm}$ in length, $20 \mathrm{~mm}$ in width and $6 \mathrm{~mm}$ thick then they were manufactured by Ningbo Newland International Trade Co. Ltd. Dimensions of the designs were determined taking into consideration that the manufacturing costs should be kept at minimum. BH curves of them were given in Figure $\mathbf{2}$ and their characteristic properties were presented in Table 2 . 


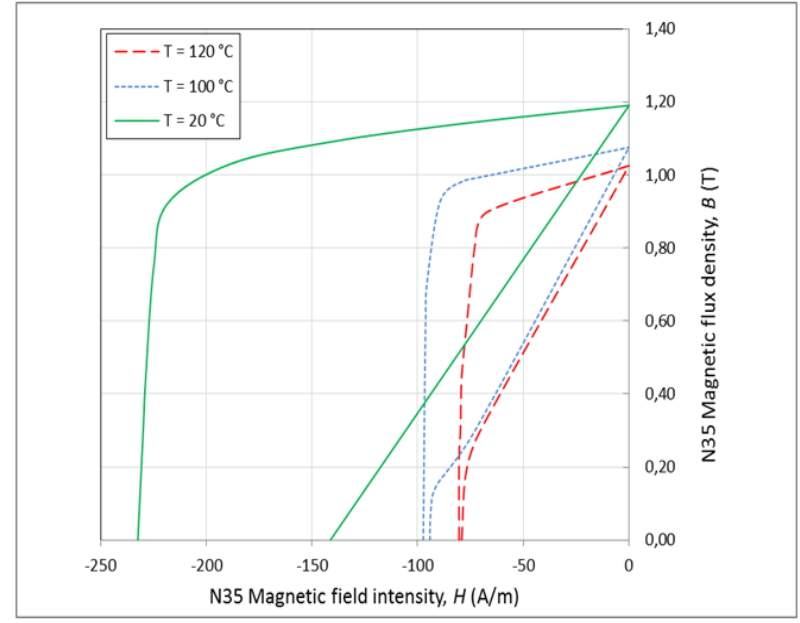

(a)

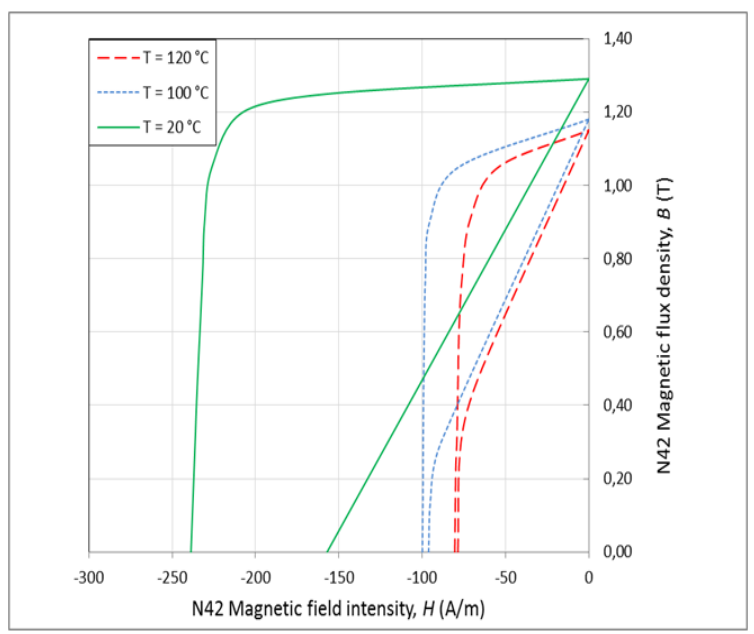

(b)

Figure 2. BH hysteresis curves of (a) N35 and (b) N42 NdFeB PMs.

Table 2. The characteristic properties of N35 and N42 NdFeB PMs.

\begin{tabular}{|l|l|l|}
\hline Properties & N35 & N42 \\
\hline Maximum energy production, $B H_{\max }\left(\mathrm{kJ} / \mathrm{m}^{3}\right)$ & $263-287$ & $318-342$ \\
\hline Remanence $($ residual induction $), B_{r}(\mathrm{~T})$ & $1.17-1.22$ & $1.28-1.32$ \\
\hline Coercive force, $H_{c}(\mathrm{kA} / \mathrm{m})$ & $\geq 868$ & $\geq 915$ \\
\hline Intrinsic coercive force, $H_{c i}(\mathrm{kA} / \mathrm{m})$ & $\geq 955$ & $\geq 955$ \\
\hline Temperature coefficient, $\beta H_{c i}\left(\% /{ }^{\circ} \mathrm{C}\right)$ & -0.6 & -0.6 \\
\hline Curie temperature, $T_{c}\left({ }^{\circ} \mathrm{C}\right)$ & 310 & 310 \\
\hline Maximum work temperature, $T_{m}\left({ }^{\circ} \mathrm{C}\right)$ & $\leq 80$ & $\leq 80$ \\
\hline
\end{tabular}

\subsection{THE INSTALLED MEASUREMENT SYSTEM}

While the manufactured IR-PMSGs with both N35 and N42 NdFeB PM rotors were being tested, a data acquisition system (DAQ) was made in order to realize measurements of the current, voltage and temperature variables of MWT in the truck test (Mamur 2015a).

Two anemometers - one was Prova AVM-03 model, $\pm 3 \%$ accuracy and 0.3-45 m/s ranges, the other was Kestrel 3000 model, $\pm 3 \%$ accuracy and $0.6-40 \mathrm{~m} / \mathrm{s}$ ranges - were used to measure the wind speed, which is the most effective variable in determining the output power. At the same time, the wind speed was also monitored via the speed display of the truck. The frequency of the MWT was obtained through a digital Multimeter - which was Brymen BM805 model and $\pm 3 \%$ accuracy - used in frequency mode. The DAQ, its application the cogging toque measurement setup in the MWT system were shown in Figure 3a and 3b.

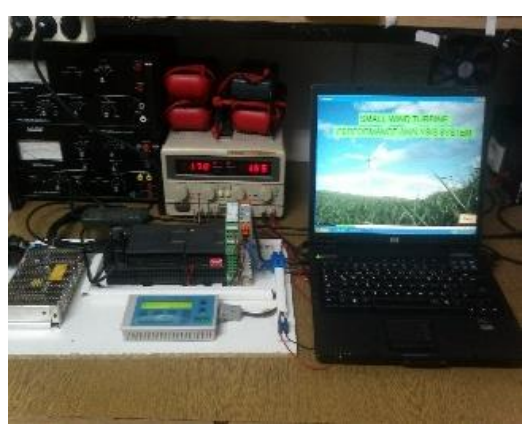

(a)

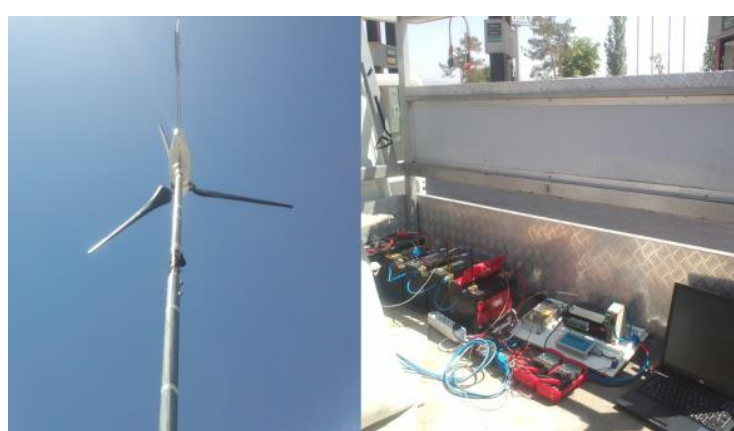

(b) 


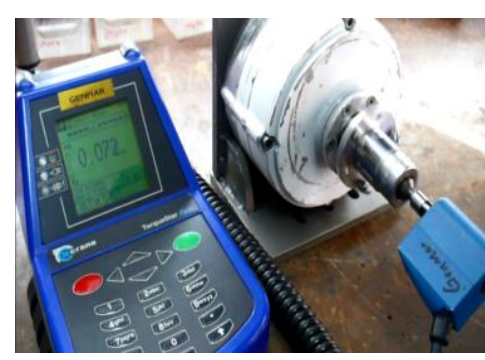

(c)

Figure 3. (a) The DAQ, (b) the application of the DAQ and (c) the cogging toque measurement setup in the MWT system.

Furthermore, a photo tachometer - which was Extect Pocket/TACH 461700 model, $\pm 3 \%$ accuracy - was used to measure the speed of the MWT as rpm. In order to minimize the measurement errors, the DAQ system was used for calculating the power output by measuring the voltage, current, and temperature as well as three other measurement devices - namely an Extect HD200 model, $\pm 1 \%$ accuracy in temperature mode and two Brymen BM805 model, $\pm 0.5 \%$ accuracy in ammeter and voltmeter modes. To define the cogging torques of the IR-PMSG for both N35 and N42 PMs rotors, a combined torque meter - which was Crane Electronic UTA-451-0020-OP model 0-5 Nm ranges transmitter and Crane Electronic TO-890-01CR-0-EUR model display - was utilized as demonstrated in Figure 3c.

\section{RESULTS}

The test data recorded for both systems with the N35 and N42 NdFeB PM rotors are illustrated comparatively in Figure 4-8. The truck test was carried out in a flat area closed to traffic and the test was executed up to $20 \mathrm{~m} / \mathrm{s}$ wind speed. To determine the input power of the MWT, the atmosphere pressure was taken from the website of Turkish State Meteorological Service as 1020 $\mathrm{hPa}$. Selected test date was determined as a day with almost no wind and the ambient temperature was measured to be $12^{\circ} \mathrm{C}$. Depending on these variables, the air density was calculated as $1.221 \mathrm{~kg} / \mathrm{m}^{3}$. On the test date, the wind speed was measure as 0.5 $\mathrm{m} / \mathrm{s}$ and the truck test was done towards the wind direction. The wind speed value was also considered to the calculations.

While the cut-in speed for the MWT system where the PMSG with the N35 NdFeB PM rotor is employed was measured as 2.7 $\mathrm{m} / \mathrm{s}$, the cut-in speed for the system with the N42 NdFeB PM rotor was measured as $4.1 \mathrm{~m} / \mathrm{s}$.

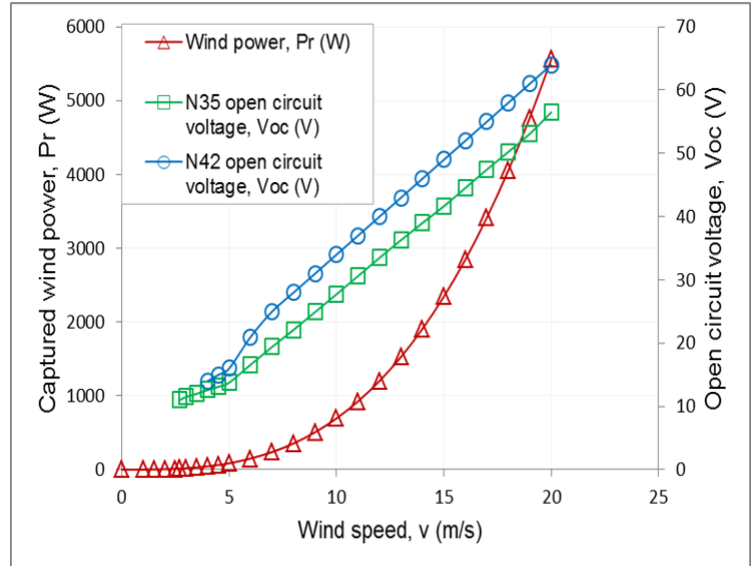

Figure 4. The DC open circuit voltage and wind input power as a function of the instantaneous wind speed.

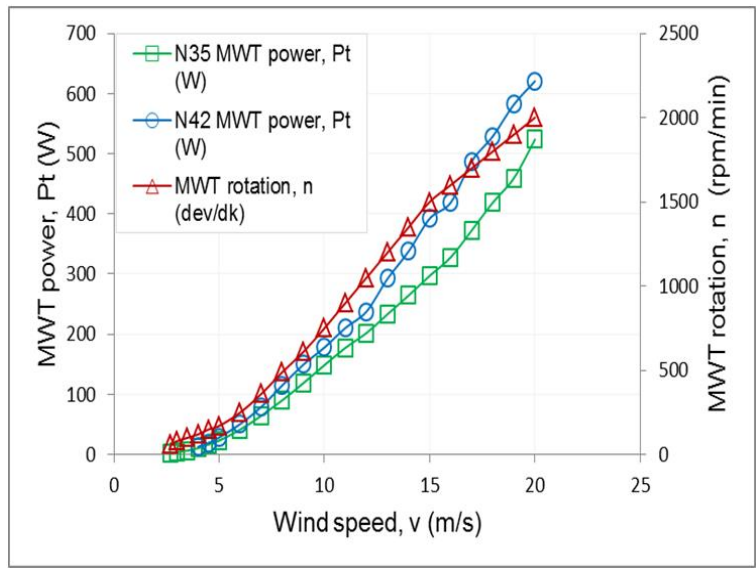

Figure 5. The speed and the power generated from the MWT as a function of the instantaneous wind speed. 


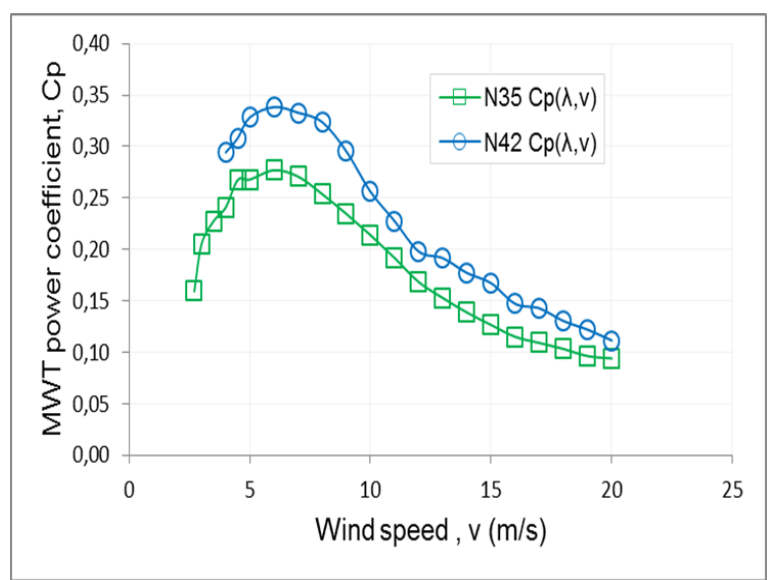

Figure 6. The power coefficient of the MWT as a function of the instantaneous wind speed.

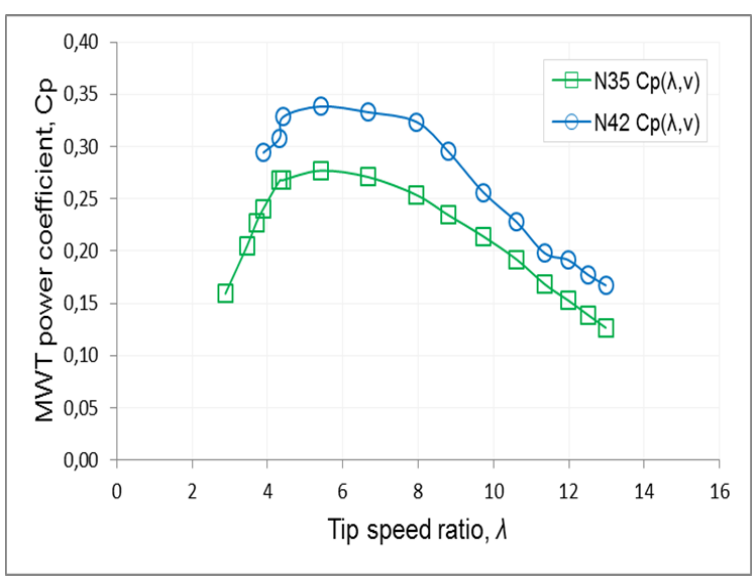

Figure 7. The power coefficient depending on the tip speed ratio (TSR).

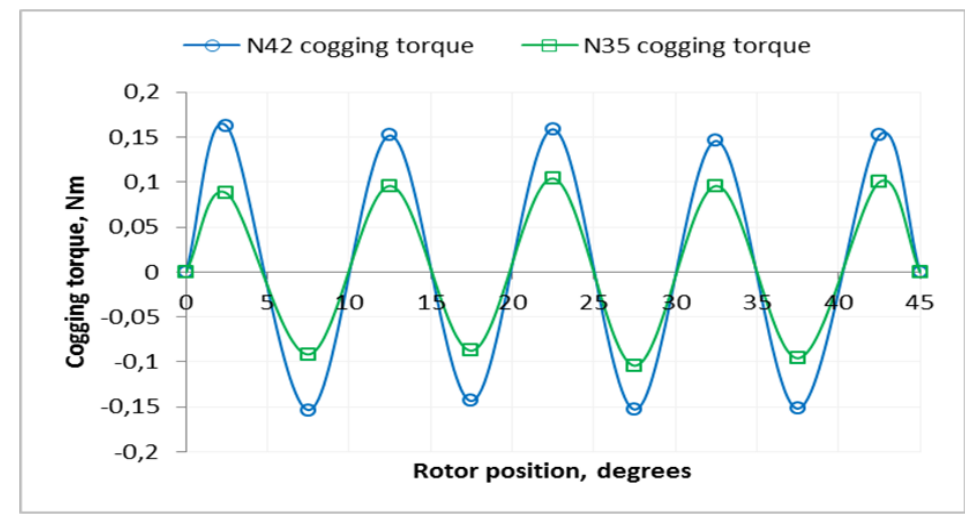

Figure 8. The cogging torque values of the PMSGs with both N35 NdFeB and N42 NdFeB PM rotors.

\section{DISCUSSION}

When the IR-PMSG using N42 NdFeB PMs rotor was employed in the MWT system, the nominal output power was obtained as $210 \mathrm{~W}$ at $11 \mathrm{~m} / \mathrm{s}$ wind speed. However, the nominal output power was measured as $177 \mathrm{~W}$ at $11 \mathrm{~m} / \mathrm{s}$ wind speed when the IRPMSG using N35 NdFeB PMs rotor was employed in the MWT system. The usage of N42 NdFeB PMs increased the power by $18.6 \%$. While the power coefficient value of the MWT system using the IR-PMSG with N35 NdFeB PMs rotor was 0.277, the same value for the system using N42 NdFeB PMs rotor increased up to 0.338 .

On the other hand, the cogging torque of the MWT system using N42 NdFeB PMs was found almost 1.7 times more than the other. While the cogging torque of the MWT employing N42 NdFeB PMs was measured $0.17 \mathrm{Nm}$, the cogging torque of MWT employing N35 NdFeB PMs was $0.1 \mathrm{Nm}$. In Figure 8, the cogging torque values were plotted from positive maximum to negative maximum. As it can be seen in the Figure 8, the same values were not achieved for the same rotor degree as a result of manufacturing difficulties. For example, while the cogging torque value at $12.5^{\circ}$ was measured $0.152 \mathrm{Nm}$ for the MWT employed N42 NdFeB PMs, the value at $32.5^{\circ}$ was taken 0.145 . During the test, the intermediate values were not shown for the cogging torque values.

The high cogging torque in the MWT employing N42 NdFeB PMs caused high cut-in speed of $4.1 \mathrm{~m} / \mathrm{s}$, whereas, the MWT employing N35 NdFeB PMs was operated at a cut-in speed of $2.7 \mathrm{~m} / \mathrm{s}$. The generated electrical energy of the MWT employing N42 NdFeB PMs was higher than the MWT employing N35 NdFeB PMs. Furthermore, the generated electrical energy of MWTs is relatively lower at low wind speeds. Keeping in mind that the generated electrical energy is a function of the cube of wind speed, the generated electrical energy through the MWT employing N42 NdFeB PMs compensated the high cogging torque and cut-in owing to the achieved performance improvement via the N42 PMs neither changing the weight and the shape of any part of MWT nor increasing the turbine load. Although it is a disadvantage for the customers in rural areas with low wind speeds, it is expected that the disadvantage can be overcome through the use of multi-wing models.

The installation cost of the MWT system employing the IR-PMSG with N35 NdFeB PMs rotor was about 2,500 $€$ for end users (Mamur 2015a). N42 PMs utilized on rotor surface of the IR-PMSG represented an additional cost of $20 €$. When the entire system cost was taken into account, the additional cost from the use of these magnets was below $1 \%$. The annual energy production and the generated electrical energy cost in this MWT system was calculated to be $431 \mathrm{kWh} /$ year and $0.29 € / \mathrm{kWh}$ by using the power curve and Rayleigh wind speed distribution over one year period at a nominal wind speed of $5 \mathrm{~m} / \mathrm{s}$. By the implemented 
performance optimization, the increase of $18.6 \%$ in nominal power generation could be acknowledged and assessed as an efficiency improvement.

\section{CONCLUSION AND FUTURE PERSPECTIVES}

In the applied study, two rotors with N35 and N42 NdFeB PMs, which had the same geometry were designed and manufactured in order to optimize the efficiency of MWTs by employing IR-PMSGs. Thus, the system output power was raised by about $18.6 \%$ at the nominal power value. The power coefficient was increased from 0.277 to 0.338 through changes in employed PM type rotors. The modification did not bring any remarkable extra costs.

On the other hand, the cogging torque increased 1.7 times, which in turn increased the cut-in value from $2.7 \mathrm{~m} / \mathrm{s}$ to $4.1 \mathrm{~m} / \mathrm{s}$. However, the higher cut-in value presents a problem, which would be overcome with the new wing models or the change in the number of blades for customers residing in areas with low wind speed.

In the future extensions of the study, some optimization issues are going to be addressed in order to minimize the high cogging torque caused by N42 NdFeB PMs by employing the same application assemblies while sustaining or further improving the increase in the output power of the MWT. Moreover, the new studies will focus on OR-PMSG designs and blade structures of MWTs to reduce the manufacturing cost of the PMSGs. The outcomes of these future studies will be presented to literature as a whole.

\section{ACKNOWLEDGEMENTS}

This project was supported by the Scientific and Technological Research Council of Turkey (TÜBİTAK) under Grant $114 \mathrm{E} 419$.

\section{REFERENCES}

Ani, S. O., Polinder, H. \& JFerreira, A.. (2013). Comparison of energy yield of small wind turbines in low wind speed areas. IEEE Trans. Sustainable Energy, 4(1): 42-49. doi:10.1109/TSTE.2012.2197426.

Bianchini, C., Davoli, M. Immovilli, F. \& Lorenzani, E. (2014). Design optimization for torque ripple minimization and poles cost reduction with hybrid permanent magnets'. In: IEEE 40th Annual Conf. of Industrial Electronics Society (IECON) Conference 29 October-1 November 2014, Dallas, TX, USA, pp. 483-489.

Chung, D. W., \& You, Y. M. (2015). Cogging torque reduction in permanent-magnet brushless generators for small wind turbines. Journal of Magnetics 20 (2): 176-185. doi:10.4283/JMAG.2015.20.2.176.

Coey, J. M. D. (2012). Permanent magnets: Plugging the gap. Scripta Materialia, 67(6): 524-529. doi:10.1016/j.scriptamat.2012.04.036.

Daili, Y., Gaubert, J. P. \& Rahmani, L. (2015). Implementation of a new maximum power point tracking control strategy for small wind energy conversion systems without mechanical sensors. Energy Conversion and Management 97: 298-306. doi:10.1016/j.enconman.2015.03.062.

Dosiek, L., \& Pillay, P.2007. Cogging torque reduction in permanent magnet machines. IEEE Trans. Industry Applications, 43 (6): 1565-1571. doi:10.1109/TIA.2007.908160.

Hostettler, J., \& Wang, X. (2015). Sliding mode control of a permanent magnet synchronous generator for variable speed wind energy conversion systems. Systems Science \& Control Engineering, 3(1): 453-459. doi:10.1080/21642583.2015.1082513.

İskender, İ., \& Genç, N. (2009). Investigation of wind turbine driven double output induction generator and obtaining its maximum power using fuzzy logic control method. Journal of The Faculty of Engineering and Architecture of Gazi University, 24(2): 343350.

Islam, R., Husain, I., Fardoun, A. \& McLaughlin, K. (2009). Permanent-magnet synchronous motor magnet designs with skewing for torque ripple and cogging torque reduction. IEEE Trans. Industry Applications, 45(1): 152-160. doi:10.1109/TIA.2008.2009653.

Kim, H. J., Kim, D. Y. \& Hong, J. P. (2014). Structure of concentrated-flux-type interior permanent-magnet synchronous motors using ferrite permanent magnets. IEEE Trans. Magnetics, 50(11): 1-4. doi:10.1109/TMAG.2014.2323818.

Kim, J. W., Kim, S. H., Song, S. Y. \& Kim, Y. D. (2013). Nd-Fe-B permanent magnets fabricated by low temperature sintering process. Journal of Alloys and Compounds, 551: 180-184. doi.10.1016/j.jallcom.2012.10.058.

Lebsir, A., Bentounsi, A., Benbouzid, M. \& Mangel, H. (2015). Electric generators fitted to wind turbine systems: An up-to-date comparative study. Journal of Electrical Systems, 11(3): 281-295. 
Liu, C., Zhu, J., Wang, Y., Lei, G., Guo, Y. \& Liu, X. (2014). A low-cost permanent magnet synchronous motor with SMC and ferrite PM. In: 17th International Conf. on Electrical Machines and Systems (ICEMS) Conference, 22-25 October 2014, Hangzhou, China, pp. 397-400.

Löewe, K., Brombacher, C., Katter, M. \& Gutfleisch, O. (2015). Temperature-dependent Dy diffusion processes in Nd-Fe-B permanent magnets. Acta Materialia, 83: 248-288. doi:10.1016/j.actamat.2014.09.039.

Mamur, H. (2015a). Design, application, and power performance analyses of a micro wind turbine. Turkish Journal of Electrical Engineering \& Computer Science, 23(6): 1619-1637. doi:10.3906/elk-1401-174.

Mamur, H. (2015b). Comparison of cogging torque reduction methods for micro wind turbines using permanent magnet synchronous generator. In: Unitech 2015 International Scientific Conference, 20-21 Nov. 2015, Gabrovo, Bulgaria, pp. 63-67.

Mamur, H. (2016). Performance evaluation for a permanent magnet synchronous generator with interior rotor of N35 and N42 $\mathrm{NdFeB}$ permanent magnets having same geometry in small wind turbines. International Journal of Energy Applications and Technology 3(2): 50-54.

Mamur, H., Ari, M., Korkmaz, F. \& Topaloglu, I. (2013). The importance of supervisory control and data acquisition systems for wind turbines. In: Unitech 2013 International Scientific Conference, 22-23 November 2013; Gabrovo, Bulgaria. pp. $121-126$.

Mamur, H., Ari, M., Korkmaz, F., Topaloglu, I., Cicek, A. \& Bektas, E. (2015). Micro wind turbines and power performance analyses. In: Unitech 2015 International Scientific Conference, 20-21 November 2015; Gabrovo, Bulgaria, pp. 59-62.

Mamur, H., Bektaş, E., Cicek, A., Korkmaz, F., Topaloglu, I, \& Ari, M. (2017). Application of wind monitoring system based on programmable logic controller. KU International Journal of Engineering Research and Development, 9(2): 33-42.

Mamur, H., Topaloglu, I., Korkmaz, F., Ari, M. \& Atacak, I. (2014). Design and experimental analysis for reduction of cogging torque by pole shifting in permanent magnet synchronous generator. Elektronika ir Elektrotechnika, 20(8): 39-43.

McFarland, J. D., Jahns, T. M., El-Refaie, A. M. \& Reddy, P. B. (2014). Effect of magnet properties on power density and fluxweakening performance of high-speed interior permanent magnet synchronous machines. In: IEEE Energy Conversion Congress and Exposition (ECCE) Conference, 14-18 September 2014, Pittsburgh, PA, USA, pp. 4218-4225.

Petrow, I., \& Pyrhönen, J. (2013). Performance of low-cost permanent magnet material in PM synchronous machines. IEEE Trans. Industrial Electronics, 60(6): 2131-2138. doi:10.1109/TIE.2012.2191757.

Pyrhönen, J., Ruoho, S., Nerg, J., Paju, M., Tuominen, S., Kankaanpää, H., Stern, R., Boglietti, A. \& Uzhegov, N. (2015). Hysteresis losses in sintered NdFeB permanent magnets in rotating electrical machines. IEEE Trans. Industrial Electronics, 62(2): 857-865. doi:10.1109/TIE.2014.2354597.

Sergeant, P., \& Van den Bossche, A. P. (2014). Influence of the amount of permanent-magnet material in fractional-slot permanentmagnet synchronous machines. IEEE Trans. Industrial Electronics, 61 (9): 4979-4989. doi:10.1109/TIE.2013.2258310.

Skomski, R., Manchanda, P., Kumar, P., Balamurugan, B., Kashyap, A. \& Sellmyer, D. J. (2013). Predicting the future of permanent-magnet materials. IEEE Trans. Magnetics, 49(7): 3215-3220. doi:10.1109/TMAG.2013.2248139.

Slusarek, B., Kapelski, D., Antal, L., Zalas, P. \& Gwoździewicz, M. (2014). Synchronous motor with hybrid permanent magnets on the rotor. Sensors, 14(7): 12425-12436. doi:10.3390/s140712425.

Tarimer, I., \& Ocak C. (2009). Performance comparision of internal and external rotor structured wind generators mounted from same permanent magnets on same geometry. Elektronika ir Elektrotechnika, 92(4): 65-70.

Tripathi, S. M., Tiwari, S. M. \& Singh, D. (2015). Grid-integrated permanent magnet synchronous generator based wind energy conversion systems: A technology review. Renewable and Sustainable Energy Reviews, 51: 1288-1305. doi:10.1016/j.rser.2015.06.060.

Vaimann, T., Kallaste, A., Kilk, A. \& Belahcen, A. (2013). Magnetic properties of reduced Dy NdFeB permanent magnets and their usage in electrical machines. In: IEEE Africon Conference, 9-12 September 2013, Pointe-Aux-Piments, Mauritius, pp. 1-5.

Yağmur, A. \& Çam, E. (2017). Implementation of feasibility analysis of wind and solar energy on the web base. KU International Journal of Engineering Research and Development, 9(1): 1-10.

Yıldırız, E., \& Aydemir, M. T. (2009). Analysis, design and implementation of an axial flux, permanent magnet machine to be used in a low power wind generator. Journal of The Faculty of Engineering and Architecture of Gazi University, 24(3): 525-531.

Zhang, S., Xu, J., Junak, J., Fiederling, D., Sawczuk, G., Koch, M., Schalja, A., Podack, M. \& Baumgartner, J. (2012). Permanent magnet technology for electric motors in automotive applications. In: IEEE II. Electric Drives Production Conference (EDPC), 15-18 October 2012, Nuremberg, Germany, pp. 1-11. 